P-ISSN 2722-2101, E-ISSN 2722-4201

Layalitas Kreativitas

Program Studi Ekonomi Manajemen Universitas Pamulang

Aledi Masyarakat Kreatif

Jurnal LOKABMAS Kreatif Vol.02,No.02.Juli 2021 Hal.68-74

Email:jurnalkreatif.manajemen@gmail.com

\title{
PENYULUHAN PENTINGNYA PEMAHAMAN TENTANG KEMANFAATAN DAN KEMUDARATAN MEDIA SOSIAL DI DESA KAWUNGLARANG, KECAMATAN RANCAH, KABUPATEN CIAMIS
}

\author{
Yoyon M Darusman ${ }^{1}$, Bastianon $^{2}$, Susanto $^{3}$, Bambang Wiyono $^{4}$, Dyas Mulyani Benazir ${ }^{5}$ \\ ${ }_{1,2,3,4}$ Dosen Magister Hukum Universitas Pamulang ${ }^{5}$ Dosen D3 Sekretari Universitas Pamulang \\ EMAIL : yoyon.darusman@yahoo.co.id, dosen00111@unpam.ac.id, \\ susanto@unpam.ac.id, dosen00050@unpam.ac.id
}

\begin{abstract}
ABSTRAK
Tujuan kegiatan ini adalah untuk memberikan pemahaman kepad masyarakat Desa Kawunglarang, Kecamatan Rancah, Kabupaten Ciamis mengenai pemanfaatan media social serta mudarat aau dampak negative penggunaan media sosial. Adapun, pelaksanaan kegiatan terbagi dari beberapa kategorisasi seperti: 1. Tahap Pra Pelaksanaan: a. bahwa tim pengabdi men-survey lokasi ke Desa Kawunglarang, Kecamatan Rancah, Kabupaten Ciamis guna berdiskusi perihal jadwal, peserta dan tema. b. bahwa tim pengabdi, mempersiapakan peralatan dan perlengkapan seperti laptop, spidol, dan papan tulis/kertas besar, proyektor dan plakat penghargaan kepada tuan rumah serta konsumsi untuk seluruh peserta dan pihak terkait. c. bahwa tim menghitung dan merencanakan anggaran belanja termasuk modal awal, post biaya operasional dan biaya lain yang dianggap perlu. 2. Tahap Pelaksanaan: bahwa tim pengadbi akan menggunakan metode ceramah, metode tanya-jawab interaktif dan menggunakan metode role playing; 3. Tahap Paska Pelaksanaan: bahwa tim akan membuat laporan akhir kepada tiga pihak yakni: Desa Kawunglarang, tim pengabdi dan pihak Lembaga Penelitian dan Pengabdian Masyarakat. Hasil kegiatan ini masyarakat Desa Kawunglarang, Kecamatan Rancah, Kabupaten Ciamis lebih memahami mengenai manfaat dan mudarat dari pemakaian media sosial, sehingga merek alebih bijak menggunakan media sosial.
\end{abstract}

Kata Kunci : Media Sosial, Manfaat, Mudarat

\section{ABSTRACT}

The purpose of this activity is to provide understanding to the people of Kawunglarang Village, Rancah District, Ciamis Regency regarding the use of social media and the disadvantages or negative impacts of using social media. Meanwhile, the implementation of activities is divided into several categories such as: 1. Pre-Implementation Stage: a. that the service team surveyed the location in Kawunglarang Village, Rancah District, Ciamis Regency in order to discuss schedules, participants and themes. $b$. that the service team prepares equipment and supplies such as laptops, markers and large whiteboards / paper, projectors and plaques of appreciation to the host and consumption for all participants and related parties. c. that the team calculates and plans the expenditure budget including initial capital, post operational costs and other costs deemed necessary. 2. Implementation Stage: that the pengadbi team will use the lecture method, the interactive question and answer method and use the role playing method; 3. Post Implementation Stage: that the team will make a final report to three parties, namely: Kaunglarang Village, community service team and the Institute for Research and Community Service. The results of this activity, the people of Pedeslohor Village, Adiwerna District, Tegal Regency better understand the benefits and disadvantages of using social media, so brands are wiser to use social media.

Keywords: Social Media, Benefits, Mudarat 


\section{PENDAHULUAN}

Bangsa kita sudah tidak asing lagi dengan adanya ghibah yang beredar di media sosial. Mulai mengghibahkan tokoh politik, tokoh ekonomi, bahkan tokoh agama sekalipun. Fenomena seperti itu membuat para pendukung korban semakin membenci pelaku dan klimaks pun tak bisa dihindari. Hingga akhirnya muncul perpecahan sesama saudara. Hal tersebut terjadi akibat kurang cerdasnya seseorang dalam menggunakan media sosial. Bahaya ghibah secara langsung sudah termaktub dalam al-Quran surat alHujurat ayat 12 Allah berfirman: "Wahai orang-orang yang beriman! Jauhilah banyak dari prasangka, sesungguhnya sebagian prasangka itu dosa dan janganlah kamu mencari-cari kesalahan orang lain dan janganlah ada di antara kamu yang menggunjing sebagian yang lain. Apakah ada di antara kamu yang suka memakan daging saudaranya yang sudah mati? Tentu kamu merasa jijik. Dan bertakwalah kepada Allah, sesungguhnya Allah Maha Penerima tobat, Maha Penyayang." Ghibah didefinisikan sebagai menggunjing orang lain. Diibaratkan sebagai manusia yang memakan daging bangkai saudaranya yang sudah mati. Lalu, apakah mereka yang hobby ghibah di media sosial tak ingat akan ayat di atas? Sehingga tak segan-segan seseorang mampu membuat problem yang menimbulkan kemerosotan akhlaq-akhlaq yang baik. Jika sudah terjadi fenomena semacam itu, bagaimana hal yang sepatutnya kita lakukan sebagai seorang muslim? Pertama, mempertimbangkan baik dan buruknya saat hendak berbicara. Karena hati seseorang akan terasa sakit bila tertimpa suatu kata yang sangat melukai hati. Kedua, percaya diri agar tidak mudah terpengaruh oleh orang lain. Karena di zaman sekarang banyak konflik yang terjadi sebab terpengaruh oleh perkataan orang lain yang kebenarannya masih sangat dipertanyakan. Oleh karena itu kita sebagai umat Islam hendaknya mampu membentengi diri dari hal-hal semacam itu. Ketiga, menjauhi sifat hasad. Perlu diketahui bahwa hasad tidak boleh dilakukan kecuali dua hal. Apa itu? Yakni, orang yang dianugerahi ilmu dan harta oleh Allah, lalu digunakannya untuk membela kebenaran, dan orang yang dianugerahi ilmu oleh Allah lalu dengan ilmu itu ia gunakan untuk memutuskan suatu perkara, dan ia mengajarkannya kepada orang lain. Di zaman modern seperti sekarang hendaknya tiap-tiap jiwa mampu membentengi diri dengan tidak menuliskan hal negatif di dalam media sosial. Facebook yang sudah dikenal di berbagai negara, sekarang banyak terisi oleh berita hoax, berita ambigu, dan berita yang belum pasti kebenarannya. WhatsApp yang terkenal sebagai media untuk mengirim pesan singkat dan untuk mengeratkan ukhuwah lewat grup, sekarang ada yang masih mampu men-share informasi yang berisi cacian, makian, adu domba, perpecahan, serta intervensi dengan pihak lain. Padahal semua yang dikerjakan manusia di dunia, kelak akan dipertanggungjawabkan di akhirat. Sebagaimana sabda Nabi Muhammad shallallahu 'alaihi wa sallam: "Kalian semua adalah pemimpin, dan akan mempertanggungjawabkan yang dipimpinnya...." (Mutafaqun 'Alaih). Jika seorang muslim sudah mengetahui bahwa semua hal akan dipertanggungjawabkan, maka setidaknya harus berusaha untuk menggunakan media secara bijak, berpikir jernih, dan ramah. Jika bangsa kita telah mengimplementasikan kebijakan yang bagus, maka Insya Allah akan tercipta negara yang baldatun thoyyibatun wa robbun ghoffur. kita mungkin perlu mencermati mengapa majalah asal Inggris, The Economist, dalam edisi 4-10 November 2017 sampai menulis headline 'Social media's threat to democracy?' Apakah sedemikian parahnya situasi media sosial yang ada saat ini sehingga The Economist tak ragu menyebutnya sebagai 'ancaman bagi demokrasi'. Dalam konteks apa, The Economist sampai pada kesimpulan demikian? Editorial yang diajukan The Economist menyebutkan 'media sosial pernah tampil dengan suatu harapan bahwa mereka akan memberikan pencerah-an pada dunia politik, penyampaian informasi yang akurat, dan komunikasi yang tak hentihentinya ditujukan untuk membantu orangorang baik untuk memberantas korupsi, memerangi kebodohan, serta mengungkap kebohongan'. Akan tetapi, melihat 


\section{Loyalitas Kreativitas \\ P-ISSN 2722-2101, E-ISSN 2722-4201 \\ Aldi Masyarakat Kreatif \\ Program Studi Ekonomi Manajemen Universitas Pamulang \\ Jurnal LOKABMAS Kreatif Vol.02,No.02.Juli 2021 Hal.62-67 \\ Email:jurnalkreatif.manajemen@gmail.com}

kenyataannya, harapan tadi tinggallah harapan yang menjadi niatan baik, tetapi sulit terwujud sebagai kenyataan. Berkaca pada pemilihan umum di Amerika pada 2015, data yang dikutip The Economist menunjuk pada kenyataannya banyak sekali warga Amerika yang mengakses misinformasi yang dilakukan Rusia dalam platform seperti Facebook dan kanal Youtube. The Economist menambahkan fenomena politik menjadi makin buruk tidak hanya terjadi di Amerika, tetapi juga di Spanyol dan Afrika Selatan. The Economist menyimpulkan 'penggunaan media sosial tidak hanya menyebabkan keterbelahan dalam masyarakat, tetapi juga penyebarluasan keterbelahan itu'. Majalah ini berharap media sosial, walaupun telah disalahgunakan sejumlah pihak, dengan suatu keinginan kuat, masyarakat dapat meredamnya dan mimpi tentang pencerahan dalam masyarakat masih akan bisa terwujud. Kita sama-sama tahu bahwa fenomena hoaks telah mencemari atau menebar racun dalam demokrasi yang kita jalani saat ini. Filsuf Jerman, Jurgen Habermas, percaya bahwa masyarakat perlu menerapkan apa yang ia sebut sebagai demokrasi deliberatif, yaitu kesempatan kepada banyak pihak untuk menyampaikan pendapat mereka, yang paling berbeda sekalipun, dan kemudian membiarkan masyarakat mengambil keputusan atas informasi yang beragam tersebut. Sekarang ini banyak sekali pemberitaan yang kebenarannya masih belum jelas dan tidak ada fakta di dalamnya. Berita - berita seperti ini sepertinya sudah menjadi salah satu makanan masyarakat dunia. Dari berita seperti ini, ada banyak bahaya berita hoax yang sering kali membahayakan sebuah wilayah, kepentingan umum dan lainnya. Nah, kita saat ini akan sedikit membahas mengenai bahaya berita hoax. Berita hoax adalah berita yang mana isinya belum jelas fakta dan kebenarannya. Berita seperti ini biasa disebut sebagai berita bohong, kabar burung sebab belum jelas kebenarannya. Umumnya, berita - berita bohong ini hadir di tengah - tengah sebuah event penting. Ini bisa terjadi pada event pemilihan atau pemilu, sebuah kejadian dan lainnya. Namun, tak jarang pula berita hoax ditampilkan ketika hari - hari biasa. Melalui pendidikan PKM dengan tujuan membangun karakter anti hoax juga diharapkan munculnya rasa tanggung jawab untuk memberantas hoax dan memberikan contoh pada masyarakat luas tidak hanya dari tuturan, tetapi juga melalui perbuatan yang mencerminkan karakter yang ulet, jujur, toleran, dan lain sebagainya. Maka, berdasarkan uraian di atas penulis hendak mengadakan Pengabdian Kepada Masyarakat dengan judul: "PENYULUHAN PENTINGNYA PEMAHAMAN TENTANG KEMANFAATAN DAN KEMUDARATAN MEDIA SOSIAL DI DESA KAWUNGLARANG, KECAMATAN RANCAH, KABUPATEN CIAMIS"

Pengabdian Kepada Masyarakat (PKM) akan diselenggarakan pada 01 April 2021 sampai dengan 03 April 2021 di Desa Kawunglarang, Kecamatan Rancah, Kabupaten Ciamis. Dari acara PKM ini dan menindaklanjuti problem mitra yang ditangkap oleh tim, maka berikut beberapa solusi yang ditawarkan, yakni : a. Dengan adanya kegiatan ini akan membuat warga termotivasi menjadi contoh yang baik di masyarakat terbentuknya nilai-nilai kejujuran, tanggung jawab, keberanian, kegigihan, kepedulian, disiplin, kreatif, kebersamaan, kesederhanaan b. Sehingga akan menghasilkan adanya penyamaan persepsi di masyarakat bahwa tugas pencegahan hoox tidak saja merupakan tanggungjawab pemerintah saja akan tetapi juga menjadi tangungjawab bersama. c. Terbentuknya komunitas warga anti hoax di tingka desa.

\section{METODE PELAKSANAAN}

Kegiatan Pengabdian Kepada Masyarakat (PKM) yang dilaksanakan pada tanggal 01 April 2021 sampai dengan 03 April 2021 telah berjalan dengan baik dan lancar. Sebelum tanggal tersebut juga dilakukan komunikasi secara intens sebagai analisis awal. Kegiatan ini diikuti Kepala Desa, Aparat Desa, Badan Permusyawaratan Desa, Ketua RT dan RW, Ibu-ibu penggerak PKK dan muda- 
mudi dari Desa Kawunglarang, Kecamatan Rancah, Kabupaten Ciamis.

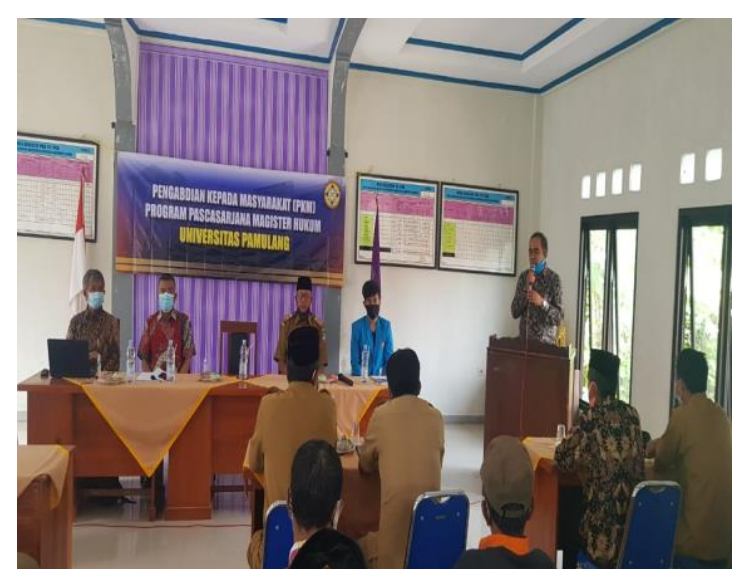

Gambar 1 : Penyampaian Materi Oleh Dr. Yoyon M. Darusman, SH, MM

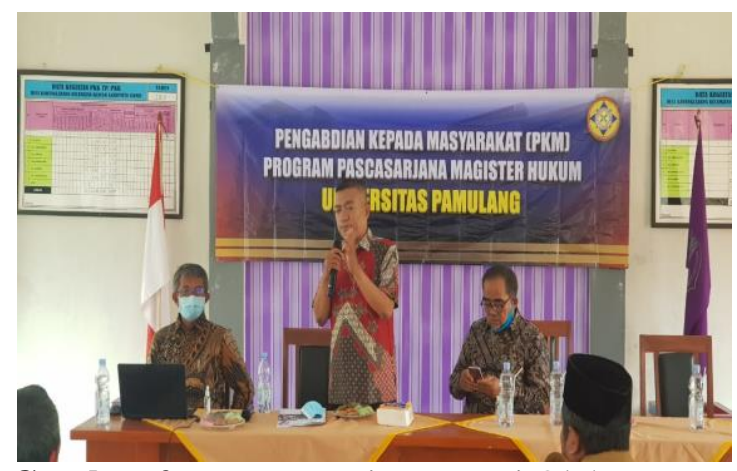

Gambar 2 : Penyampaian Materi Oleh Dr. Susanto, $\mathrm{SH}, \mathrm{MM}, \mathrm{MH}$

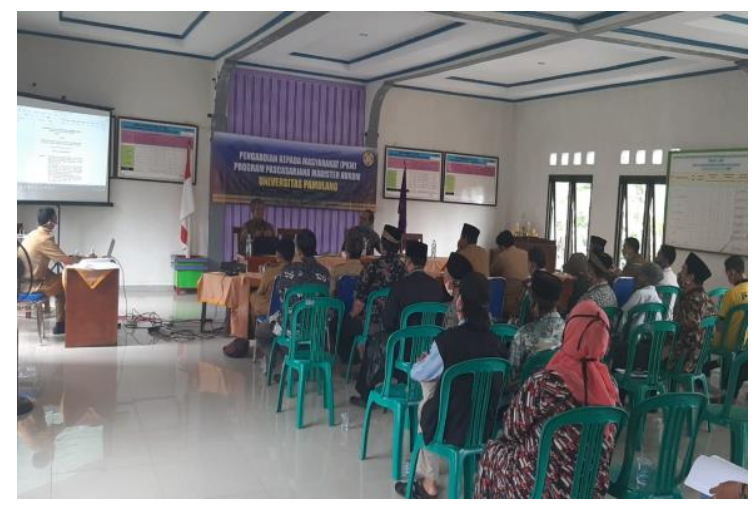

Gambar 3 : Penyampaian Materi Oleh Dr. Bambang Wiyono, $\mathrm{SH}, \mathrm{MH}$

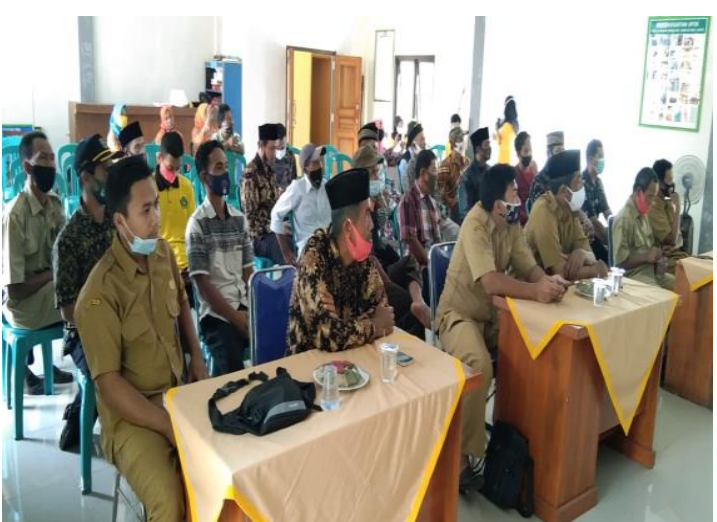

Gambar 4 : Antusiasme Peserta PKM

\section{HASIL DAN PEMBAHASAN}

Disampaikan oleh pemateri PKM bahwa Media Sosial. Saat ini penggunaan media sosial nampaknya telah menjadi bagian dari sebagian besar masyarakat Indonesia. Selain itu media sosial saat ini juga telah di jadikan sebagai tempat untuk saling mendapatkan dan menyebarkan informasi. Namun, sayangnya akibat dari penyalahgunaan sosial media dalam menyebarkan informasi juga berdampak pada banyaknya para pengguna yang masuk ke ranah hukum akibat dari penyebaran informasi pada sosial media yang tidak menggunakan etika.

Dalam upaya mengurangi permasalahan tersebut maka di perlukanlah suatu etika dalam menggunakan media sosial agar tidak saling menghina ataupun menuduh orang lain tanpa alasan yang jelas. Karena pada dasarnya hal seperti itulah yang nantinya akan terjerat hukum karena kurang hatihati dalam menyebarkan informasi pada internet. Seiring dengan berjalannya waktu maka teknologi juga semakin berkembang pesat. Saat ini hampir sebagian besar orang bisa saling berbagi informasi serta berkomunikasi secara langsung dengan menggunakan media sosial sebab dengan internet maka mereka lebih bisa menghemat waktu dan biaya.

Dalam penggunaannya, tentu kita di berikan kebebasan agar bisa berkomunikasi dengan siapa saja. Namun yang sering di salah artikan disini adalah, bebas bukan berarti tanpa etika. Alangkah baiknya apabila kita mengetahui etika apa saja yang 
harus di perhatikan pada saat menggunakan jejaring sosial. Tidak sedikit permasalahan sosial yang terjadi akibat kurangnya kesadaran masyarakat dalam beretika dalam sosial media. Justru para pengguna terkadang dibutakan oleh berita yang tidak benar akibat dari hasutan yang beredar pada media sosial. Berikut beberapa hal penting mengenai etika dalam menggunakan media sosial. Etika dalam Berkomunikasi Pada saat melakukan komunikasi dengan memanfaatkan media sosial, biasanya banyak yang cenderung melupakan etika dalam berkomunikasi. Hal ini di buktikan dengan banyaknya kata-kata kasar yang kerap kali muncul pada saat melakukan percakapan melalui jejaring sosial, baik yang sengaja dan tidak sengaja.

Alangkah baiknya apabila sedang melakukan komunikasi pada jaringan internet menggunakan Bahasa yang sopan dan layak. Biasakanlah untuk menggunakan Bahasa yang tepat dengan siapapun pada saat kita berinteraksi, termasuk saat berinteraksi melalui media sosial. Hindari Penyebaran SARA, Pornografi dan Aksi Kekerasan Alangkah baiknya apabila kita tidak menyebarkan informasi yang mengandung unsur SARA (Suku, Agama dan Ras) serta pornografi pada jejaring sosial. Biasakan untuk menyebarkan hal-hal yang berguna dan tidak menimbulkan konflik antar sesama. Hindari juga mengupload foto kekerasan seperti foto korban kekerasan, foto kecelakaan lalu lintas maupun foto kekerasan dalam bentuk lainnya. Jangan menambah kesedihan para keluarga korban dengan menyebarluaskan foto kekerasan karena mungkin saja salah satu dari keluarganya berada di dalam foto yang Anda share.

Jangan mengajarkan generasi muda mengenai hal kekerasan melalui foto kekerasan yang di upload secara terangterangan pada media sosial. Kroscek Kebenaran Berita Saat ini tentu tidak jarang kalau kita menemukan berita yang menjelekan salah satu pihak di media sosial. Hal inilah yang terkadang bertujuan demi menjatuhkan nama pesaing dengan menyebarkan berita yang hasil rekayasa.

Maka dari itu, pengguna media sosial dituntut agar lebih cerdas lagi saat menangkap sebuah informasi, apabila Anda ingin menyebarkan informasi tersebut, alangkah bijaknya jika Anda melakukan kroscek terlebih dahulu atas kebenaran informasi tersebut. Menghargai Hasil Karya Orang Lain Pada saat menyebarka informasi baik dalam bentuk foto, tulisan maupun video milik orang lain maka biasakan untuk mencantumkan sumber informasi sebagai salah satu bentuk penghargaan atas hasil karya seseorang. Jangan membiasakan diri untuk serta merta mengcopy-paste tanpa mencantumkan sumber informasi tersebut. Jangan Terlalu Mengumbar Informasi Pribadi Ada baiknya Anda harus bersikap bijak dalam menyebarkan informasi mengenai kehidupan pribadi (privasi) Anda saat sedang menggunakan media sosial. Janganlah terlalu mengumbar informasi pribadi Anda terlebih lagi informasi mengenai nomor telepon atau alamat rumah Anda.

Hal tersebut bisa saja membuat kontak lain dalam daftar Anda juga akan menjadi informasi bagi mereka yang ingin melakukan tindak kejahatan kepada diri Anda. Jadi pergunakanlah media sosial sebaik dan sebijak mungkin terlebih lagi dalam hal penyebaran informasi. Biasakan untuk selalu berpikir terlebih dahulu sebelum Anda bertindak.

Ada berapa metode dalam pengabdian ini, yaitu: 1. Pre test Untuk melihat pengetahuan warga terhadap karakter anti hoax. Hal ni dilakukan agar warga memahami mengenai karakter-karekater yang harus ada pada warga agar membentuk jiwa yang antihoax. 2. Metode Ceramah Metode ceramah ini dipilih untuk memberikan penjelasan tentang medsos dan aspek-aspeknya, penyebab dan dampak medsos, upaya perlawanan terhadap medsos, pentingnya budaya anti medsos bagi pendidikan, implementasi budaya anti medsos bagi warga. ceramah dilakukaan dengan menyiapkan PPT materi. materi yang digunakan sebaik mungkin agar menarik dan penyampaian materi didasarkan pada slide yang telah disiapkan. 3. Metode Tanya Jawab Metode tanya jawab sangat penting bagi para peserta pelatihan pada saat menerima penjelasan tentang materi, dengan metode ini 
memungkinkan warga menggali pengetahuan sebanyak-banyaknya tentang pendidikan karakter anti korupsi. Tanya jawab dilakukan untuk memperdalaam mengenai materi yang telah disampaikan. 4 . Setelah materi selesai dipaparkan, dilanjutkan dengan diskusi berupa tanya jawab antara pemateri dengan peserta. Diskusi dilakukan agar peserta lebih memahami materi yang telah disampaikan. Melalui diskusi, sosialisasi tidak hanya sekedar transfer knowledge saja melainkan dapat sharing pengalaman maupun permasalahan yang sedang dihadapi mitra. 5. Metode Simulasi Metode simulasi ini sangat penting diberikan kepada para peserta pelatihan untuk memberikan ksempatan mempraktekan materi pelatihan yang diperoleh. Harapannya, peserta pelatihan akan benar-benar menguasai materi pelatihan yang diterima, mengetahui tingkat kemampuannya menerapkan kegiatan yang mendukung program pemberantasan korupsi dan program pendidikan karakter anti hoax secara tehnis dan kemudian mengidentifikasi kesulitankesulitan (jika masih ada) untuk kemudian dipecahkan secara bersama-sama

\section{SIMPULAN}

Berdasarkan hasil kegiatan PKM pada pada Desa Kawunglarang, Kecamatan Rancah, Kabupaten Ciamis dengan metode penyuluhan menunjukkan bahwa :

1. Secara umum warga peserta PKM memahami akan arti penting, manfaat dan mudaratnya media social jika tidak digunakan dengan bijak.

2. Warga peserta PKM sangat senang mendapatkan wawasan mengenai media sosial.

\section{DAFTAR PUSTAKA}

Darusman, Y. M., Bastianon, B., Susanto, S., Benazir, D. M., \& Setiawan, T. (2021). Pentingnya Pemahaman Tentang Kemanfaatan Dan Kemudaratan Media Sosial. Abdi Laksana: Jurnal Pengabdian Kepada Masyarakat,2(1), 173-179.

Darusman, Y. M., Susanto, S., Anggraeni, R. D., Bachtiar, B., \& Bastinaon, B.
(2020). Sosialisasi Undang-Undang Perlindungan Anak Dan Kdrt Kelurahan Pulau Panggang Kabupaten Kepulauan Seribu. Jurnal Lokabmas Kreatif, 1(1), 76-82.

Darusman, Y. M., Susanto, S., Anggraeni, R. D., Bachtiar, B., \& Bastinaon, B. (2020). Sosialisasi Undang-Undang Perlindungan Anak Dan Kdrt Kelurahan Pulau Panggang Kabupaten Kepulauan Seribu. Jurnal Lokabmas Kreatif, 1(1), 76-82.

Darusman, Y. M., Susanto, S., Anggraeni, R. D., Gueci, R. S., \& Yanto, O. (2019). Penyuluhan Peraturan PerundangUndangan Pemilihan Umum (Pemilu) Tahun 2019 (Studi Kasus Pada Politeknik Ilmu Pemasyarakatan (Poltekip) Kementerian Hukum Dan Ham Ri, Depok, Jawa Barat). Jurnal Abdi Masyarakat Humanis, 1(1).

Darusman, Y. M., Susanto, S., Wiyono, B., Iqbal, M., \& Bastianon, B. (2021). BIMBINGAN TEKNIS PEMBUATAN PERATURAN DESA DI DESA KAWUNGLARANG, KECAMATAN RANCAH, KABUPATEN CIAMIS. Jurnal Abdimas Tri Dharma Manajemen, 2(2), 125-129.

Elburdah, R. P., Pasaribu, V. L. D., Rahayu, S., Septiani, F., \& Metarini, R. R. A. (2021). Mompreneur Penopang Perekonomian Keluarga Di Masa Pandemi Covid-19 Dengan Bisnis Online Pada Kelurahan Pondok Benda. Abdi Laksana: Jurnal Pengabdian Kepada Masyarakat,2(1), 75-82.

Priadi, A., Pasaribu, V. L. D., Virby, S., Sairin, S., \& Wardani, W. G. (2020). Penguatan Ekonomi Kreatif Berbasis Sumber Daya Desa Dikelurahan Rempoa. Abdi Laksana: Jurnal Pengabdian Kepada Masyarakat, 1(3), 356-358.

Pasaribu, V. L. D., Jannah, M., Fazar, M., Putra, S. P., Monalisa, M., \& Sofa, M. (2021). MENINGKATKAN PRODUKTIVITAS USAHA DIMASA PANDEMI PADA IBU PKK RT 004/003 KELURAHAN SAWAH BARU CIPUTAT, TANGERANG SELATAN. Abdi Laksana: Jurnal 
Pengabdian Kepada Masyarakat,2(2), 295-301.

Susanto, M. I. (2019). Kedudukan Hukum People Power Dan Relevansinya Dengan Hak Kebebasan Berpendapat Di Indonesia. Volksgeist: Jurnal Ilmu Hukum Dan Konstitusi, 2(2), 225-237.

Susanto, S., \& Iqbal, M. (2019). Pengabdian Kepada Masyarakat Dalam Sinergitas Akademisi Dan TNI Bersama Tangkal Hoax Dan Black Campaign. CARADDE: Jurnal Pengabdian Kepada Masyarakat,2(1), 8-16.

Susanto, S., \& Iqbal, M. (2020, February). Dinamika Penegakan Hukum Pada Konteks Keterbukaan Informasi Keuangan Partai Politik. In Proseding Seminar Nasional Akuntansi (Vol. 2, No. 1).

Susanto, S., Darusman, Y. M., Bachtiar, B., Gueci, R. S., \& Santoso, B. (2021). MENGGUNAKAN MEDIA SOSIAL RAMAH HUKUM. Jurnal ABDIMAS Tri Dharma Manajemen, 2(1), 72-78.

Susanto, S., Herdiana, D., \& Iqbal, M. (2021). KEWENANGAN DINAS KEPENDUDUKAN DAN CATATAN SIPIL MENOLAK PENGAJUAN PERMOHONAN PENCATATAN ADOPSI ANAK ATAS PUTUSAN PENGADILAN AGAMA (Analisis Putusan No. 379Pdt. P2020PA. Tgrs.). Jurnal Surya Kencana Dua: Dinamika Masalah Hukum dan Keadilan, 7(2), 167-193.

Wiyono, B., Arofa, E., Wulansari, E. M., \& Susanto, S. (2020). Sosialisasi UndangUndang Kdrt Dan Perlindungan Anak. Jurnal Abdimas Tri Dharma Manajemen, 1(3), 42-47

Yanto, O., Susanto, S., Darusman, Y. M., Wiyono, B., \& Gueci, R. S. (2020). Sosialisasi Dan Pelatihan E-Litigasi Di Lembaga Bantuan Hukum Unggul Tangerang Selatan Guna Meningkatkan Profesinalisme Dalam Rangka Pendampingan Masyarakat Pencari Keadilan Melalui Aplikasi Komputer. Jurnal Abdimas Tri Dharma Manajemen, 1(2).

Yanto, O., Susanto, S., Nugroho, A., Santoso, B., \& Gueci, R. S. (2020).
Sosialisasi Kekayaan Intelektual Guna Menumbuhkembangkan Usaha Dalam Rangka Menghadapi Persaingan Global Pada Revolusi 4.0. Abdi Laksana, 1(2). 
Loyalitas Kreativitas

Aldi Masyarakat Kreatif
P-ISSN 2722-2101, E-ISSN 2722-4201

Program Studi Ekonomi Manajemen Universitas Pamulang

Jurnal LOKABMAS Kreatif Vol.02,No.02.Juli 2021 Hal.62-67

Email:jurnalkreatif.manajemen@gmail.com 